\title{
PENGEMBANGAN DESAIN BAHAN AJAR FISIKA BERBASIS E-MODUL PADA MATERI MOMENTUM
}

\author{
Nadah Qolbi Shobrina*, Indra Sakti, Andik Purwanto
}

\author{
Program Studi Fisika Fakultas Keguruan dan Ilmu Pendidikan Universitas Bengkulu \\ J1. WR. Supratman, Kandang Limun, Bengkulu \\ E-mail*: nadahqolbishobrina@gmail.com
}

\begin{tabular}{c|c|c|c}
\hline Diterima 23 Oktober 2019 & Direvisi 11 April 2020 & Disetujui 24 April 2020 & Dipublikasikan 29 April 2020 \\
\hline \multicolumn{4}{c}{ https://doi.org/10.33369/jkf.3.1.33-40 } \\
\hline
\end{tabular}

\begin{abstract}
ABSTRAK
Penelitian ini bertujuan untuk mengembangkan bahan ajar fisika berbasis E-Modul. Penelitian ini merupakan penelitian pengembangan yang dilaksanakan dalam lima tahap yaitu potensi dan masalah, studi literatur dan pengumpulan informasi, desain produk, validasi desain, dan desain teruji. Sampel atau sumber data penelitian ini yaitu guru fisika dan siswa SMAN 2 Kota Bengkulu kelas X MIPA D. Instrumen yang digunakan dalam penelitian ini yaitu lembar observasi, lembar angket guru dan siswa, lembar angket uji validasi tim ahli. Hasil penelitian menunjukkan bahwa bahan ajar fisika berbasis e-Modul yang dikembangkan termasuk dalam kategori valid dan merupakan desain teruji karena mendapatkan respon positif dengan persentase total uji validitas yaitu $80,6 \%$ dan serta memiliki reliabilitas tinggi pada validitas aspek isi dan penyajian dengan nilai koefisien sebesar 0,9 dan 0,88 , aspek bahasa nilai koefisien 0,79 dengan kategori sangat tinggi, dan reliabilitas aspek media 0,91 dengan kategori sangat tinggi. Berdasarkan penelitian pengembangan dan pembahasan yang dilakukan, didapatlah desain bahan ajar fisika berbasis $e$-modul pada materi momentum di SMAN 2 Kota Bengkulu yang valid dan reliable.
\end{abstract}

Kata Kunci: Bahan Ajar Fisika, E-Modul, Momentum, Penelitian pengembangan.

\begin{abstract}
This research aimed to develop physics teaching materials based on E-module. This research was is a development research conducted in five stages, namely potention and problem, literature study and information gathering, product design, design validation, and tested design .The sample or data source of this research were the Physic Teacher and Student of SMAN 2 Bengkulu, class of X MIPA D. The instruments used in this research are observation sheet, teacher and student questionnaire, test questionnaire of expert team validation test. The results showed that the e-module based physics teaching materials developed included in the category good validity and as a tested design for getting a positive response with the percentage of total validity test is $80.6 \%$ and also had reliability on the content aspect and served with coefficient value equal 0.9 and 0.88 , the coefficient value language aspect 0.79 with category very high reliability and reliability media aspect 0,88 with category very high. Based on research development and discussion conducted, resulting of e-module material design on momentum material at SMAN 2 Bengkulu was valid and reliable.
\end{abstract}

Keywords: Physics Teaching Material, E-module,Momentum, Research development

\section{PENDAHULUAN}

Perkembangan teknologi informasi dan komunikasi (TIK) telah memberikan pengaruh terhadap dunia pendidikan termasuk dalam proses pembelajaran. Kemajuan ilmu pengetahuan dan teknologi telah berpengaruh terhadap penggunaan alat-alat bantu mengajar disekolah-sekolah dan lembaga pendidikan lainnya [1]. Perkembangan TIK tersebut juga dipengaruhi dari keberadaan internet. Kehadirannya telah memberikan dampak terhadap kehidupan dalam berbagai aspek. Keberadaan internet pada masa kini cukup menjadi sebuah kebutuhan bagi manusia untuk menghadapi perkembangan global, yang mana kondisi ini juga dapat memberikan pengaruh terhadap perilaku peserta didik dan dapat pula mempengaruhi gaya belajar peserta didik. Dengan kata lain setiap orang ataupun termasuk peserta didik perlu meningkatkan kualitas dirinya untuk dapat beradaptasi dengan tuntutan yang berkembang dalam menghadapi tantangan. 
Hal baru yang sedang berkembang saat ini adalah cyber teaching atau pengajaran maya, yang merupakan suatu proses pengajaran yang menggunakan internet. Istilah lain yang popular ialah $e$ learning. E-learning adalah pembelajaran yang menggunakan rangkaian elektronik (LAN, WAN, atau internet) untuk menyampaikan isi pembelajaran [2]. Salah satu perkembangan dari e-learning dalam dunia pendidikan yaitu berupa transformasi buku cetak menjadi sebuah bahan ajar berupa $e$ book. E-book adalah singkatan dari elektronik book merupakan buku dalam versi digital, yang dapat digunakan melalui perangkat elektronik [3]. E-book membantu pendidik dalam mengefektifkan dan mengefisiensikan waktu pembelajaran, dengan berkembanganya $e$-book, maka berkembang pula sumber bahan ajar berbasis E-Modul. E-Modul merupakan suatu paket pengajaran yang memuat satu unit konsep dari bahan ajar yang disajikan dalam bentuk digital [4]. Cara menggunakan $E$ Modul sangat mudah, hanya memerlukan laptop atau handphone berbasis android yang online, dan untuk membuatnya juga cukup mudah. Pembuatan E-Modul cukup memerlukan aplikasi microsft word atau PDF dan calibre. Calibre merupakan perangkat lunak yang gratis, open source dan lintas platform dalam desain serta bias berjalan di Linux, OSX dan Windows. Perangkat lunak ini menyimpan file e-book dalam database bersama dengan metadata dengan mudah diedit untuk menggambarkan setiap buku, serta sinkron dengan e-book reader [5].Jika terjadi kesalahan dalam pembuatan bisa langsung diperbaiki dengan cara di edit. Menggunakan ataupun membuat E-Modul tidak diperlukan tinta maupun kertas sehingga biaya yang digunakan lebih hemat. E-Modul dapat digunakan oleh guru sebagai media pembelajaran dan sebagai bahan ajar mandiri bagi peserta didik. Peserta didik dapat mengetahui seberapa jauh tingkat pemahamannya terhadap materi yang telah disajikan dengan menggunakan E-Modul, karena pada E-Modul juga berisi evaluasi untuk mengetahui hasil belajar peserta didik. Pada E-Modul terdapat pula gambar yang membuat E-Modul terlihat lebih menarik untuk digunakan.

Kurikulum 2013 yang diterapkan telah menuntut peserta didik agar dapat melakukan pembelajaran secara mandiri, namun peserta didik tidak disediakan buku yang sesuai dengan kurikulum 2013 untuk membeli, peserta didik hanya disediakan untuk membeli LKS, sedangkan pada LKS hanya berisi sedikit materi. Pada kurikulum 2013 ini juga diharuskan memanfaatkan perkembangan teknologi dan informasi, guru berperan penting dan harus menguasai tentang teknologi informasi dan komunikasi, serta mampu memfasilitasi pembelajaran anak secara efektif. Selain peserta didik, guru juga dapat memanfaatkan perkembangan TIK yang ada. Guru dapat memanfaatkan internet untuk menunjang proses pembelajaran, dan dengan didukung perkembangan perangkat komputer maupun handphone berbasis android, guru dan peserta didik melakukan interaksi tidak hanya melalui tatap muka saja tetapi juga melalui media.

Berdasarkan hasil observasi di SMAN 2 Kota Bengkulu tahun ajaran 2017/2018 pada tanggal 5 Maret 2018 di kelas X MIPA D, siswa hanya menggunakan LKS sebagai sumber bahan ajar, sedangkan siswa tidak disediakan untuk membeli buku paket, siswa hanya dipinjamkan buku paket pada saat proses pembelajaran di sekolah. Metode yang digunakan guru dalam pembelajaran sudah cukup baik akan tetapi guru juga membutuhkan bahan ajar berbasis elektronik yang dapat dijadikan sumber belajar bagi peserta didik untuk mendukung kurikulum 2013 yang digunakan sekolah saat ini, dimana siswa dituntut untuk dapat belajar sacara mandiri serta dapat dapat memanfaatkan perkembangan TIK. Semua siswa sudah cukup pandai menggunakan handphone berbasis android, laptop dan alat-alat elektronik lainnya yang dihubungkan dengan internet. SMAN 2 Kota Bengkulu memiliki 4 ruangan laboratorium komputer yang dilengkapi dengan jaringan internet dan dapat digunakan oleh guru maupun pesera didik.

Dari observasi yang telah dilakukan, salah satu inovasi yang tepat untuk dikembangkan di SMAN 2 Kota Bengkulu yaitu E-Modul, yang memanfaatkan teknologi dan komputer sebagai perangkat media interaktifnya. E-Modul dapat diakses melalui laptop atau handphone berbasis android dan bisa dimanfaatkan oleh guru maupun siswa. Berdasarkan hasil observasi di atas, maka dilakukan penelitian yang berjudul "Pengembangan Desain Bahan Ajar Fisika Berbasis E-Modul pada Materi Momentum di SMAN 2 Kota Bengkulu”. Adapun tujuan penelitian ini adalah mengembangkan bahan ajar fisika berbasis E-Modul. 


\section{METODE PENELITIAN}

Penelitian yang dilakukan pada penilitian ini adalah R \& D (Reseacrh and Development). penelitian pengembangan ini menggunakan langkah $R$ \& $D$ level 1 . Dalam penelitian pengembangan level 1 yang dilakukan hanya menghasilkan produk, dan rancangan tersebut di validasi secara internal (pendapat ahli dan praktisi) tetapi tidak di uji secara eksternal (pengujian lapangan) [6].

Instrumen penelitian pertama menggunakan lembar observasi sebagai pengumpulan data untuk mengetahui potensi dan masalah. Pada instrumen penelitian kedua menggunakan lembar angket kebutuhan untuk mengumpulkan data guna mengetahui produk apa yang perlu dikembangkan berdasarkan potensi dan masalah yang telah ditemukan. Selanjutnya pada instrumen penelitian ketiga menggunakan lembar angket tim ahli untuk mengumpulkan data dalam pengujian internal terhadap rancangan produk. Untuk kisi-kisi angket tim ahli dapat dilihat pada tabel 1.

\section{Tabel 1. Kisi-kisi Angket Tim Ahli}

\begin{tabular}{cccc}
\hline Variabel & Aspek & Nomor item & $\begin{array}{c}\text { Jumlah } \\
\text { item }\end{array}$ \\
\hline Komponen & Isi & $1,2,3,4,5,6,7,8,9,10,11,12,13,14,15,16,17,18$ & 18 \\
Validitas E-Modul & Penyajian & $1,2,3,4,5,6,7,8,9,10,11,12$ & 12 \\
& Bahasa & $1,2,3,4,5,6,7,8$ & 8 \\
& Media & $1,2,3,4,5,6$ & 6 \\
\hline
\end{tabular}

Berdasarkan tabel 1, setiap nomor item dikoding ke dalam bentuk data kualitatif dengan skala yang digunakan adalah skala Likert. Variabel yang diukur dijabarkan menjadi indikator variabel. Kemudian indikator tersebut dijadikan sebagai tolak ukur untuk menyusun item-item yang dapat berupa pertanyaan ataupun pernyataan [7]. Skala Likert yang digunakan dalam penelitian ini adalah skala yang berjumlah 5, yaitu Sangat baik (SB) : 5, Baik (B) : 4, Cukup baik (CB) : 3, Kurang baik (KB) : 2, dan Sangat tidak baik (STB) : 1 .

Setelah memperoleh data dari angket, angket dianalisis untuk menentukan rata-rata penilaian dan tanggapan dari tim ahli, rumus untuk mencari rata-rata adalah sebagai berikut:

$$
M_{x}=\frac{\sum X}{N}
$$

dengan $M_{x}$ adalah Mean (rata-rata), $\sum X$ adalah Jumlah seluruh skor, dan $N$ adalah Banyaknya skor [8]. Selanjutnya, menghitung persentase nilai validitas menggunakan rumus perhitungan persentase skor [9] berikut.

$$
\text { Nilai Validitas }(\%)=\frac{\text { skor rata-rata }}{\text { skor tertingi }} \times 100 \%
$$

Setelah memperoleh persentase nilai validitas, nilai tersebut dikategorikan berdasarkan tabel 2 .

\begin{tabular}{ccc}
\multicolumn{3}{c}{ Tabel 2. Pemberian Nilai Validitas } \\
\hline No & Persentase & Kategori \\
\hline 1 & $0-20$ & Tidak Valid \\
2 & $21-40$ & Kurang Valid \\
3 & $41-60$ & Cukup Valid \\
4 & $61-80$ & Valid \\
5 & $81-100$ & Sangat Valid
\end{tabular}

Tabel 2 menunjukkan kategori persentase nilai validitas dengan 5 kategori, yakni Tidak Valid, Kurang Valid, Cukup Valid, Valid, dan Sangat Valid. Untuk menguji reliabilitas menggunakan rumus alpha cronbach. Rumus alpha cronbach [10] adalah sebagai berikut.

$$
\rho_{\alpha}=\frac{N}{N-1} \frac{\sigma_{A}^{2}-\sum \sigma i^{2}}{\sigma_{A}^{2}} \quad \text { atau } \quad \rho_{\alpha}=\frac{N}{N-1}\left(1-\frac{\sum \sigma i^{2}}{\sigma_{A}^{2}}\right) .
$$

Persamaan untuk menghitung varian total skor responden dan varian butir yaitu:

$$
\begin{array}{ccc}
\sigma_{A}^{2}=\frac{N \sum A^{2}}{N^{2}} & \text { dimana } & \mathrm{N}=\text { Jumlah responden } \\
\sigma_{B i^{2}}=\frac{N \sum B i^{2}-\left(\sum B i\right)^{2}}{N^{2}} \text { dimana } & \mathrm{N}=\text { Jumlah responden }
\end{array}
$$


dengan $\sum \sigma i^{2}$ adalah jumlah seluruh varian butir, $\sigma_{A}^{2}$ adalah varian skor responden, $\mathrm{N}$ adalah jumlah butir yang setara, $\rho_{\alpha}$ adalah koefisien reliabilitas, A adalah skor responden, B adalah skor butir, $\sigma_{A}^{2}$ adalah varian total skor responden (A), dan $\sum \sigma_{B i^{2}}$ adalah varian jumlah butir.

Hasil reliabilitas yang didapat dianalisis secara kuantitatif dan ditentukan interpretasi nilai reliabilitasnya. Interpretasi nilai reliabilitas [11] dapat dilihat pada tabel 3 berikut.

\begin{tabular}{cc}
\multicolumn{2}{c}{ Tabel 3. Interpretasi Reliabilitas } \\
\hline Nilai Reliabilitas & Interpretasi \\
\hline $0,00<\mathrm{r}_{11} \leq 0,20$ & Sangat rendah \\
$0,20<\mathrm{r}_{11} \leq 0,40$ & Rendah \\
$0,40<\mathrm{r}_{11} \leq 0,70$ & Sedang \\
$0,70<\mathrm{r}_{11} \leq 0,90$ & Tinggi \\
$0,90<\mathrm{r}_{11} \leq 1,00$ & Sangat Tinggi \\
\hline
\end{tabular}

Berdasarkan tabel 3, hasil reliabelitas diinterpretasikan menjadi 5 kategori yaitu sangat rendah, rendah, sedang, tinggi, dan sangat tinggi.

\section{HASIL DAN PEMBAHASAN}

\subsection{Potensi dan Masalah}

Pada tahap ini ditemukan potensi yaitu telah diterapkannya kurikulum 2013 di SMAN 2 Kota Bengkulu dan ditemukannya masalah yaitu kurangnya pemanfaatan TIK pada proses pembelajaran, sedangkan pada kurikulum 2013 siswa dituntut untuk dapat melakukan pembelajaran secara mandiri dan dapat memanfaatkan kemajuan TIK.

Tahap potensi dan masalah dilakukan dengan menggunakan lembar observasi tentang kebutuhan E-Modul. Lembar observasi dinyatakan tentang kegunaan bahan ajar fisika. Hasil dari lembar observasi kebutuhan E-Modul adalah sebagai berikut : 1) sudah diterapkannya kurikulum 2013 di SMAN 2 Kota Bengkulu, 2) bahan ajar yang digunakan di SMAN 2 Kota Bengkulu pada saat proses pembelajran fisika adalah buku paket yang dipinjamkan dari sekolah pada saat proses pembelajaran. Buku paket yang dipinjamkan tidak bisa dibawa pulang, sehingga siswa hanya memiliki buku LKS sebagai sumber bahan ajar, 3) sistem pembelajaran fisika yang digunakan di SMAN 2 Kota Bengkulu sesuai dengan sistem pembelajaran kurikulum 2013, namun masih kurang memanfaatkan teknologi informasi dan komunikasi, 4) bahan ajar yang digunakan di SMAN 2 Kota Bengkulu dapat dibeli di sekolah yaitu LKS, dan 5) fasilitas di SMAN 2 Kota Bengkulu mendukung ketersediaannya e-modul, dimana di SMAN 2 Kota Bengkulu difasilitasi 4 ruang laboratorium komputer dan juga tersedia jaringan internet yang dapat digunakan oleh guru maupun siswa.

\subsection{Studi Literatur dan Pengumpulan Informasi}

Studi literatur dari penelitian yang berjudul Pengembangan Media E-Modul Mata Pelajaran Produktif Pokok Bahasan "Instalasi Jaringan LAN (Local Area Network)" untuk Siswa Kelas XI Jurusan Teknik Komputer Jaringan di SMK Negeri 1 Labang Bangkalan Madura, disimpulkan bahwa pengembangan E-Modul telah meningkatkan hasil belajar siswa jurusan Teknik computer jaringan di SMK Negeri 1 Labang dan E-Modul yang dikembangkan baik untuk diimplementasikan sebagai media pembelajaran. E-modul yang dikembangkan berisi sebuah materi yang dilengkapi dengan evaluasi guna mengetahui peningkatan hasil belajar siswa [4].

Hasil angket kebutuhan e-modul di SMAN 2 Kota Bengkulu di kelas X MIPA D yang diisi oleh 27 siswa yaitu hanya 1 siswa yang tidak tertarik untuk mengikuti pembelajaran fisika. Dari 27 siswa terdapat 2 siswa yang tidak mengalami kesulitan dalam pembelajaran fisika pada materi momentum, namun terdapat 4 siswa yang sangat kesulitan dalam pembelajaran fisika pada materi momentum, sedangkan siswa lainnya cukup kesulitan dalam pembelajaran fisika pada materi momentum.

Dari 27 siswa hanya 3 siswa yang memiliki buku cetak sendiri, sedangkan siswa lainnya hanya memiliki bahan ajar LKS. Semua siswa di kelas X MIPA D membutuhkan sumber bahan ajar lain selain yang sudah tersedia dan tertarik belajar fisika menggunakan E-Modul. Semua 
siswa di kelas X MIPA D mempunyai handphone berbasis android, handphone berbasis android yang dimiliki siswa digunakan untuk media sosial, bermain game, browsing dan berkomunikasi. Sebanyak 4 siswa menggunakan handphone berbasis android lebih dari 5 jam, hanya 8 siswa yang menggunakan handphone berbasis android untuk membaca artikel online. Oleh sebab itu, dapat dikatakan bahwa perlu adanya pengembangan E-Modul yang bisa dimanfaatkan sebagai bahan belajar siswa agar siswa dapat melakukan pembelajaran secara mandiri.

\subsection{Desain Produk}

Tahap selanjutnya pada penelitian ini adalah mendesain produk. Langkah pertama pembuatan E-Modul adalah melakukan perencanaan perumusan unit modul terlebih dahulu meliputi silabus, kompetensi inti, kompetensi dasar serta materi pembelajaran. Materi yang digunakan adalah materi momentum. Berdasarkan silabus, kompetensi dasar pada materi momentum yaitu : 3.10 ) Menerapkan konsep momentum dan impuls, serta hukum kekekalan momentum dalam kehidupan sehari-hari dan 4.10) Menyajikan hasil pengujian penerapan hukum kekekalan momentum, misalnya bola jatuh bebas ke lantai dan roket sederhana. Materi pada desain E-Modul dikutip dari beberapa buku sesuai kebutuhan E-Modul yang dibuat. Desain awal didapat dari guru di SMAN 2 Bengkulu Utara [12] yang dapat dilihat pada gambar 1 berikut.

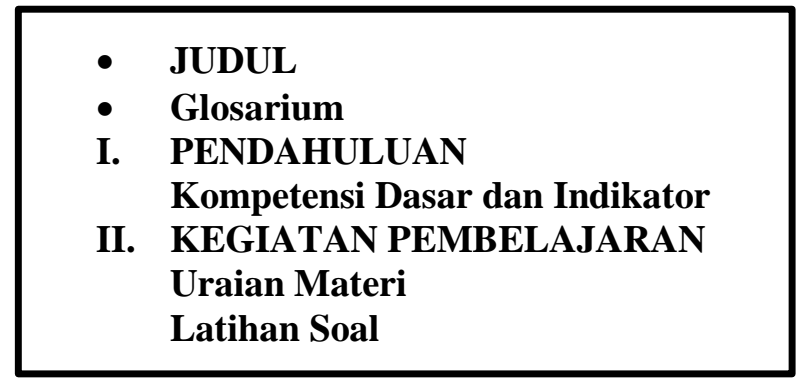

Gambar 1. Kerangka awal desain $E$-Modul

Kerangka desain awal yang didapat tersebut memiliki beberapa kelemahan, yakni materi dan gambar yang ada masih kurang serta desainnya kurang rapi dan kurang menarik. Berdasarkan hal tersebut, dikembangkanlah desain bahan ajar fisika berbasis E-Modul dengan kerangka desain $E$ Modul seperti pada gambar 2 berikut.

\section{COVER \\ DAFTAR ISI \\ GLOSARIUM \\ I. PENDAHULUAN}

A. Kompetensi Dasar dan Indikator

B. Petunjuk Penggunaan E-Modul

II. KEGIATAN PEMBELAJARAN

A. Tujuan Pembelajaran

B. Uraian Materi

1. Momentum

2. Implus

3. Hubungan Momentum dan Impuls

4. Hukum Kekekalan Momentum

5. Tumbukan

6. Penerapan Hukum Kekekalan Momentum

C. Rangkuman Materi

D. Latihan Soal

E. Penilaian Diri

III. EVALUASI AKHIR MODUL

\section{A. Soal}

B. Kunci

DAFTAR PUSTAKA

Gambar 2. Kerangka Desain E-Modul yang dikembangkan 
Berdasarkan kerangka desain E-Modul yang sudah dikembangkan, maka dibuatlah desain bahan ajar fisika berbais E-Modul pada materi momentum di SMAN 2 Kota Bengkulu.

Pada penelitian ini pembuatan desain E-Modul menggunakan aplikasi calibre, karena aplikasi calibre merupakan software gratis dan fitur di dalamnya juga gratis sehingga mudah didapat. Penggunaan aplikasi calibre cukup mudah, terutama bagi pemula yang belum pernah membuat $E$ Modul. Karena di SMAN 2 Kota Bengkulu belum pernah dikembangkannya E-Modul, maka aplikasi calibre merupakan salah satu aplikasi yang tepat digunakan pemula untuk membuat $E$ Modul. Pada aplikasi calibre sudah tersedia fitur untuk membaca E-Modul yang sudah dibuat, sehingga tidak diperlukan lagi software pembaca E-Modul.

\subsection{Validasi Desain}

Desain E-Modul yang sudah dibuat kemudian diuji validasi oleh judgement ahli dan praktisi. Validasi terdiri dari aspek isi, aspek penyajian, aspek bahasa dan aspek media. Berikut hasil uji validitas oleh tiga ahli.

Tabel 4. Hasil Uji Validitas

\begin{tabular}{crc}
\hline Aspek & Nilai Rata-rata & Kategori \\
\hline Isi & $82,22 \%$ & Sangat Valid \\
Penyajian & $81,11 \%$ & Sangat Valid \\
Bahasa & $79,16 \%$ & Valid \\
Media & $80,00 \%$ & Valid \\
Rata-rata & $80,62 \%$ & Valid \\
\hline
\end{tabular}

Berdasarkan tabel 4, desain bahan ajar fisika berbasis $E$-Modul yang sudah dikembangkan berada dalam kategori sangat valid dengan rata-rata persentase validitas isi $82,22 \%$, validasi penyajian $81,11 \%$, validitas bahasa dalam kategori valid dengan persentase $79,16 \%$, dan validitas media $80,00 \%$. Setelah mendapat hasil uji validitas selanjutnya dilakukan uji reliabilitas. Hasil uji reliabilitas ditunjukkan Tabel 5.

Tabel 5. Hasil uji reliabilitas

\begin{tabular}{cccc}
\hline No & Uji Validitas & Nilai Koefisien & Kategori \\
\hline 1 & Isi & 0,90 & Reliabilitas sangat Tinggi \\
2 & Penyajian & 0,88 & Reliabilitas Tinggi \\
3 & Bahasa & 0,79 & Reliabilitas Tnggi \\
4 & Media & 0,91 & Reliabilitas sangat Tinggi \\
\hline
\end{tabular}

Hasil uji reliabilitas dari keempat aspek yang didapat berdasarkan Tabel 5, berada dalam ketegori reliabilitas tinggi, dengan nilai koefisien aspek isi 0,90 , aspek penyajian 0,88 , aspek bahasa 0,79 dan aspek media 0,91. Kemudian hasil uji reliabilitas yang didapat termasuk dalam kategori reliabilitas tinggi dengan nilai koefisien validasi isi 0,90 , validasi penyajian 0,88 , validasi bahasa 0,79 dan validasi media 0,91 .

\subsection{Desain teruji}

Tahap terakhir pada penelitian pengembangan ini yaitu desain teruji, yang mana pada tahap ini telah dilakukan revisi berdasarkan saran dari validator agar menghasilkan desain teruji dari produk yang dikembangkan. Revisi yang dilakukan pada aspek isi yaitu perbaikan simbol dan kata yang salah, pada aspek penyajian dilakukan revisi pada keruntutan penyajian pada daftar isi dan kerapian penyusunan $E$-Modul, dan pada aspek bahasa dilakukan revisi pada penambahan gambar. Produk akhir yang telah dihasilkan dapat dilihat pada gambar 3, 4, 5, dan 6 berikut. 

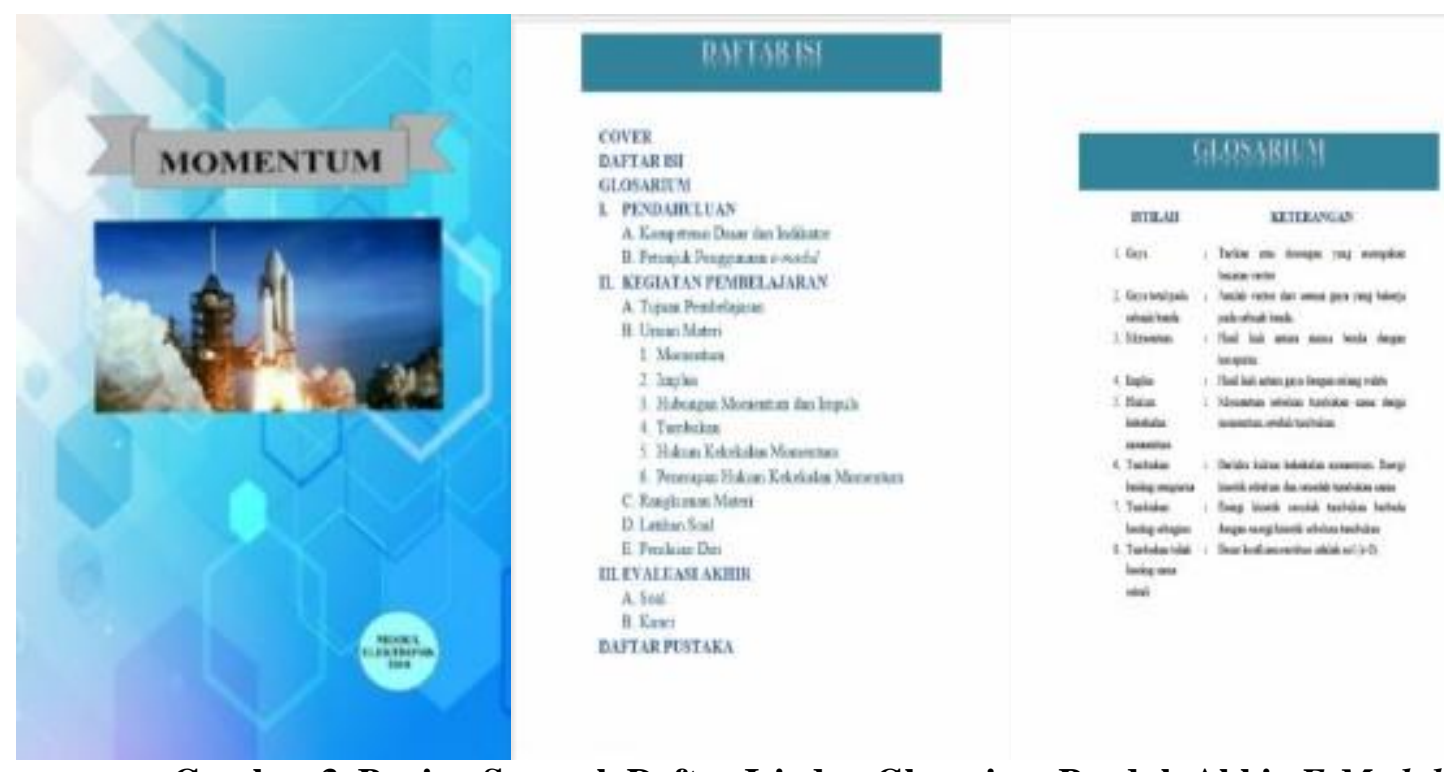

Gambar 3. Bagian Sampul, Daftar Isi, dan Glosarium Produk Akhir E-Modul

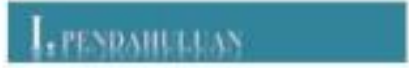

Kompeteasi Dasar :

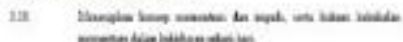

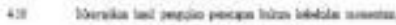

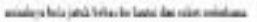

Indikater Pencapaian Kompetensi :

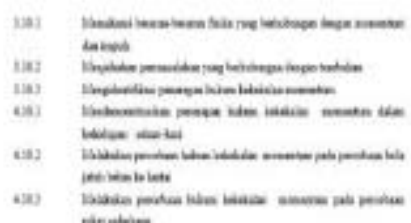

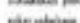

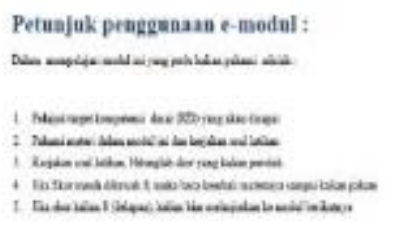

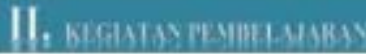

Tujasn Pembelajaran

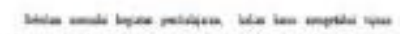

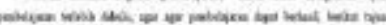

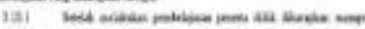

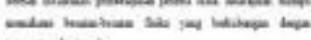

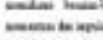

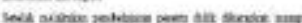

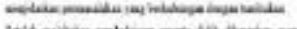

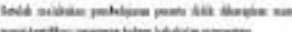
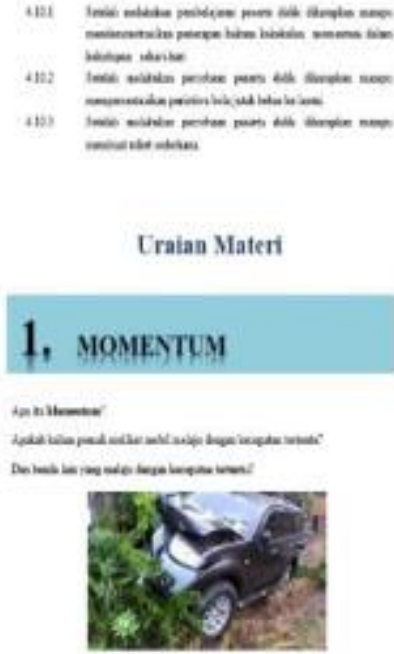

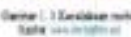

Gambar 4. Bagian Pendahuluan, Kegiatan Pembelajaran, dan Uraian Materi Produk Akhir E-Modul
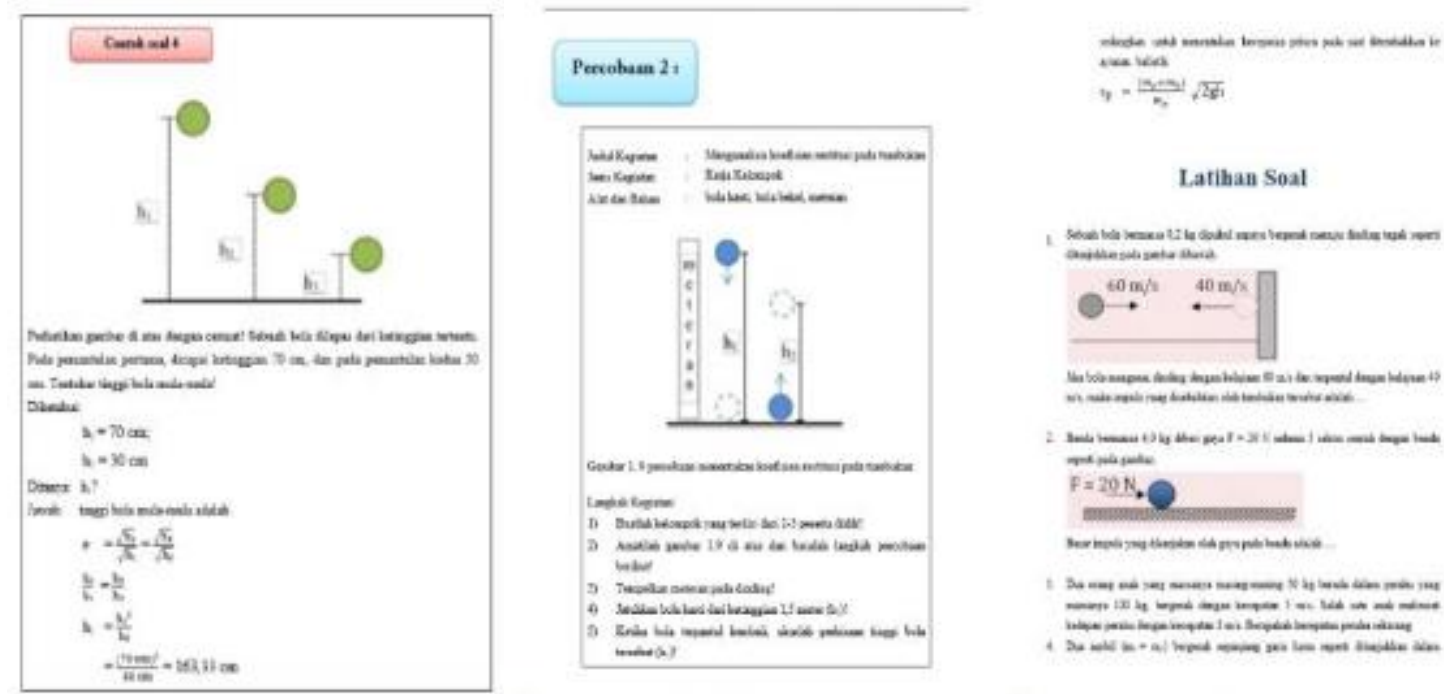

Gambar 5. Bagian Contoh Soal, Percobaan, dan Latihan Soal Produk Akhir E-Modul 

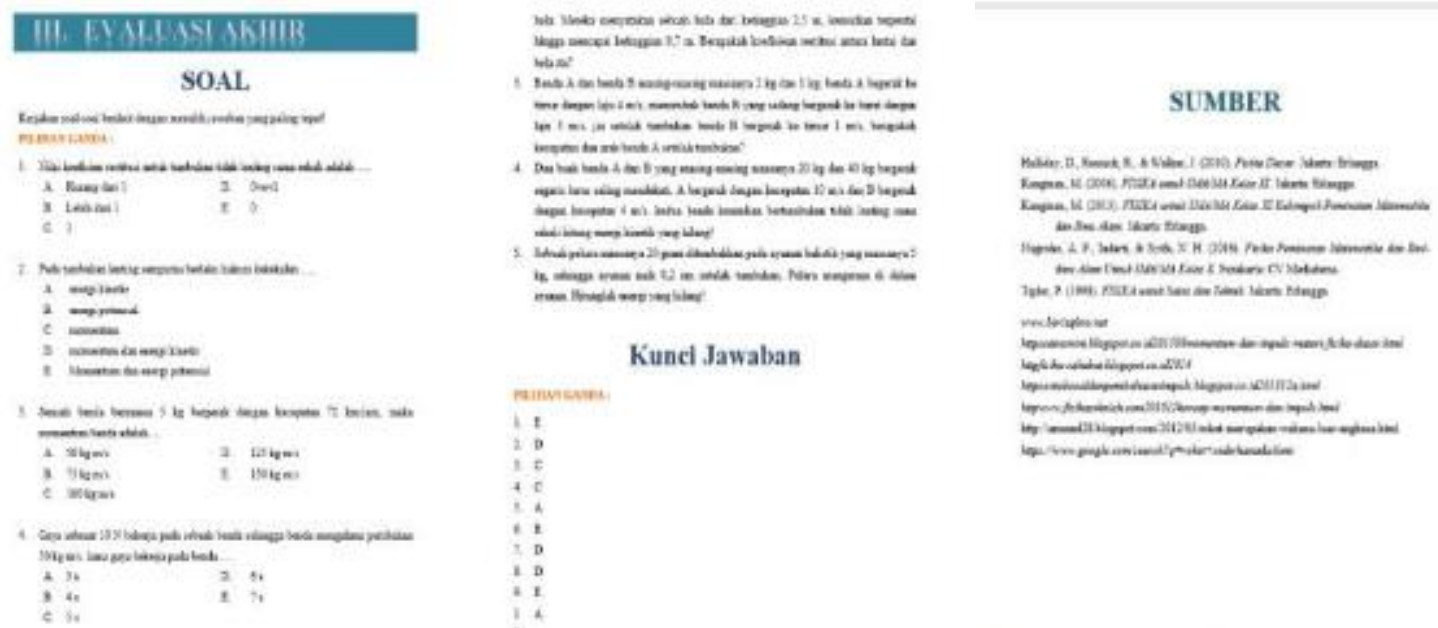

Gambar 6. Bagian Evaluasi Akhir, Kunci Jawaban, dan Sumber Produk Akhir E-Modul

Produk akhir yang telah direvisi merupakan tahap akhir dari penelitian pengembangan rancangan level 1 yaitu desain teruji yang merupakan hasil uji internal dan perbaikan dari saran tim ahli [6]. Penelitian lain juga mengungkapkan bahwa apabila E-Modul telah diuji validitasnya dan dilakukan perbaikan, maka E-Modul tersebut layak untuk digunakan [13].

\section{SIMPULAN DAN SARAN}

Kesimpulan yang didapat dari penelitian pengembangan ini yaitu desain bahan ajar fisika berbasis $E-M o d u l$ pada materi momentum yang telah dikembangkan merupakan desain yang valid dan reliable. Adapun saran yaitu sebaiknya menggunakan tabel, seperti pada penyusunan pilihan ganda dan mengatur posisi gambar menjadi in line with text agar terlihat rapi.

\section{DAFTAR PUSTAKA}

[1] Muhson, A., 2010, Pengembangan Media Pembelajaran Berbasis Teknologi Informasi. Jurnal Pendidikan Akuntansi Indonesia, No 2, Vol. 8, hal. 1-10.

[2] Rusman, Kurniawan, D., dan Riyana, C., 2013, Pembelajaran Berbasis Teknologi Informasi dan Komunikasi, Rajawali Pers, Jakarta.

[3] Fitria, T. N., dan Heliawan, Y. A., 2017, Meningkatkan Kemampuan Mahasiswa Prodi S1 Akuntansi dalam Memahami Buku, e-Book dan Artikel/Jurnal Akuntansi Berbahasa Inggris, Jurnal Akuntansi dan Pajak, No.2, Vol. 17, hal. 1-13.

[4] Fausih, M., 2015, Pengembangan Media E-Modul Mata Pelajaran Produktif Pokok Bahasan "Instalasi Jaringan LAN (Local Area Network)" untuk Siswa Kelas XI Jurusan Teknik Komputer Jaringan di SMK Negeri 1 Labang Bangkalan Madura, Jurnal Mahasiswa Teknologi Pendidikan, No. 1, Vol. 1, hal. 1-9.

[5] Saepuloh, D., 2016, Perpustakaan Elektronik (E-Library) Menggunakan Calibre. Jurnal Pari, No. 2, Vol. 2, hal. 92-96.

[6] Sugiyono, 2017, Metode Penelitian dan Pengembangan, Alfabeta, Bandung.

[7] Sugiyono, 2010, Metode Penelitian Pendidikan, Alfabeta, Bandung.

[8] Sudijono, 2009, Statistik Pendidikan, PT Rajagrafindo Persada, Jakarta.

[9] Septiani, A., Syakbaniah, dan Mufit, F., 2013, Pengembangan Bahan Ajar CD Interaktif Berbentuk Power-Point Materi Suhu dan Kalor untuk Pembelajaran Fisika Kelas X SMA, Pillar of Physics Education, Vol. 2, hal. 49-56.

[10]Susetyo, B., 2015, Penyusunan dan Analisis Tes, PT. Refika Aditama, Bandung.

[11] Jihad, A. dan Haris, A., 2012, Evaluasi Pembelajaran, Multi Pressindo, Yogyakarta.

[12] Suhari, 2017, Modul Fisika Elektronika SMA, SMAN 2 Bengkulu Utara, Tidak Diterbitkan.

[13] Nurjannati, N., Rahmad, M., dan Irianti, M., 2017, Pengembangan E-Modul Berbasis Literasi Sains pada Materi Radiasi Elektromagnetik, Jurnal Online Mahasiswa Universitas Riau, No. 2, Vol 4, hal 1-11. 